\section{CARCINOMATOUS URETHRITIS}

BY

\section{A. DICKSON WRIGHT, M.S., F.R.C.S.}

AND

\author{
R. R. WILLCOX, M.D. \\ St. Mary's Hospital, London, W.2
}

Carcinoma of the male urethra is a rare condition, and when it does occur it is usually associated with a urethral discharge. It is thus one of the many causes of a nongonococcal urethritis. The condition may be confused with other forms of urethral stricture. Harkness (1950) published a drawing in which an intrameatal carcinoma of the penis (resembling the case described below) simulated a primary meatal syphilitic chancre and was associated with a non-gonococcal urethral discharge.

Other conditions to be considered in the differential diagnosis include intrameatal chancroid, herpes genitalis or condyloma acuminatum, chronic balanitis (for example, in diabetics), erosive balanitis, the balanitis circinata sicca of Reiter's disease, balanitis xerotica obliterans (which is also associated with meatal stricture), and erythroplasia of Queyrat. Occasionally, secondary implants from a papillary carcinoma of the bladder, especially after total cystectomy, may be seen emerging from the urinary meatus. The chronic nature of the condition in a man over 40 , the history of progressive difficulty in passing urine, the presence of blood either in the discharge or in the urine, or the tendency to bleed easily during instrumentation, and, above all, the palpable induration, are factors which lead to a suspicion of carcinoma.

\section{Previously Published Cases}

Kreutzmann and Colloff (1938) collected 143 cases from the literature and added two of their own. They stated that the first case was recorded in 1861 by Hutchinson and that by 1912 Bierbaum could trace only 49 published cases. The total was increased to 112 cases by Goldstein and Abeshouse (1937).

In Kreutzmann and Colloff's material there is a marked difference in prognosis according to whether the carcinoma was situated anteriorly (including the meatus) or posteriorly in the bulbo-membranous-prostatic portion of the urethra (see Table). Of the number of different treatments used, partial amputation of the penis was employed in 29 of the anterior cases, with 26 recoveries and 3 deaths. This

Prognosis in Carcinoma of Urethra According to Site

\begin{tabular}{|c|c|c|c|c|c|}
\hline \multirow{2}{*}{\multicolumn{2}{|c|}{ Outcome }} & \multicolumn{2}{|c|}{ Anterior Cases } & \multicolumn{2}{|c|}{ Posterior Cases } \\
\hline & & No. & $\%$ & No. & $\%$ \\
\hline $\begin{array}{l}\text { Recovered } \\
\text { Died } \\
\text { No record }\end{array}$ & $\begin{array}{l}. \\
\because\end{array}$ & $\begin{array}{l}34 \\
15 \\
11\end{array}$ & $\begin{array}{l}56.7 \\
250 \\
18.3\end{array}$ & $\begin{array}{r}11 \\
58 \\
9\end{array}$ & $\begin{array}{l}74.3 \\
74.2 \\
11.5\end{array}$ \\
\hline Total &.. & 60 & 100 & 78 & 100 \\
\hline
\end{tabular}

method was regarded as satisfactory in cases in which the distal portion of the urethra was involved. Although the inguinal glands were removed in only six cases, the authors advised this procedure as a routine. In cases of posterior involvement (including the bulb) more radical measures were recommended. It is interesting to note from this material that physicians who recorded more than one case tended to diagnose later cases earlier than the first one.

\section{Case Report}

A married man aged 51 was first seen on October 8, 1954 on account of a persistent non-gonococcal urethritis. His discharge was stated to be sometimes blood-stained and there was some dysuria. He had had a transient urethritis on his honeymoon some 25 years ago and a subsequent attackwhen no extramarital relations were admitted-in 1942 . On each occasion the discharge disappeared within a few days of appropriate treatment being given. There was no history of gonorrhoea or syphilis.

His present symptoms had begun in mid-May, 1954, while overseas, and non-gonococcal urethritis was diagnosed. He was given three penicillin injections, with improvement followed by relapse. This had been followed at various times by chlortetracycline $(8 \mathrm{~g}$.), more penicillin, chloramphenicol, local therapy, a course of sulphonamides, and two courses of oxytetracycline, each of $8 \mathrm{~g}$.

On examination a circular red area of a radius of 0.5 to $0.75 \mathrm{~cm}$. was seen immediately surrounding the urinary meatus. There was a scanty urethral discharge, a smear of which showed a moderate number of pus cells but no gonococci. The urine was very hazy in the first glass and contained no sugar. A sound revealed a well-marked stricture within the meatus and there was some induration at the tip. It was not possible to pass a urethroscope. The inguinal glands were not enlarged.

At first the condition resembled balanitis xerotica obliterans with its associated meatal stricture and accompanying nongonococcal urethritis. He was therefore given a course of erythromycin, $300 \mathrm{mg}$. four times a day for five days (total $6 \mathrm{~g}$.), and twice-weekly dilatations of his stricture were undertaken. The discharge abated, the urinary haze disappeared, and his urethra was able to take a size 24 straight metal sound.

The urethra, however, still tended to bleed easily during instrumentation and the meatitis also persisted, as did the induration at the tip. A circumcision and a urethral biopsy were therefore arranged. These were done on November 22. A wedge-shaped fragment 0.6 by 0.4 by $0.4 \mathrm{~cm}$. was removed from the meatus, and histological examination showed a non-keratinizing squamous-celled carcinoma.

On November 29 a partial amputation of the penis was performed. The glans penis and $3 \mathrm{~cm}$. of the penis were removed. An indurated tumour was found around the meatus and extending into the urethra. Histology showed it to be a squamous-celled carcinoma with moderate differentiation and some pyogenic infection.

A number of observers-for example, Schrek and Lenowitz (1947)-have stressed the frequent association of carcinoma of the penis and venereal diseases. In this case there had been three attacks of urethritis, the last of which, at least in part, had been secondary to carcinoma at the meatus. To state that the carcinoma appeared at this site because of urethritis would be speculative.

Recovery was uneventful, care being taken during subsequent weeks to keep the new urinary meatus dilated at suitable intervals. The patient returned overseas during midJanuary, 1955, and was observed from time to time by his own doctor. When seen again in London on September 16, 1955, his general condition was good, the inguinal glands were not enlarged, and there were no signs of local recurrence. There was no meatal narrowing and his stream was good. Sexual intercourse had been attempted on a few occasions with his truncated penis, but its practice had been abandoned by mutual consent owing to lack of sensation.

\section{REPERENCES}

Bierbaum, J. (1912). In aug. Dissert. Leipzig.

Goldstein, A. E., and Abeshouse, B. S. (1937). Ann. Surg., 105, 213

Harkness, A. H. (1950). Non-gonococcal Urethritis, p. 187. Livingstone, Edinburgh.

Hutchinson. J. (1861). Trans. path. Soc. Lond., 13, 167.

Kreutzmann, H. A. R., and Colloff, B. (1938). J. Amer. med. Ass., 110 184

Schrek, R., and Lenowitz, H. (1947). Cancer Res., 7, 180. 